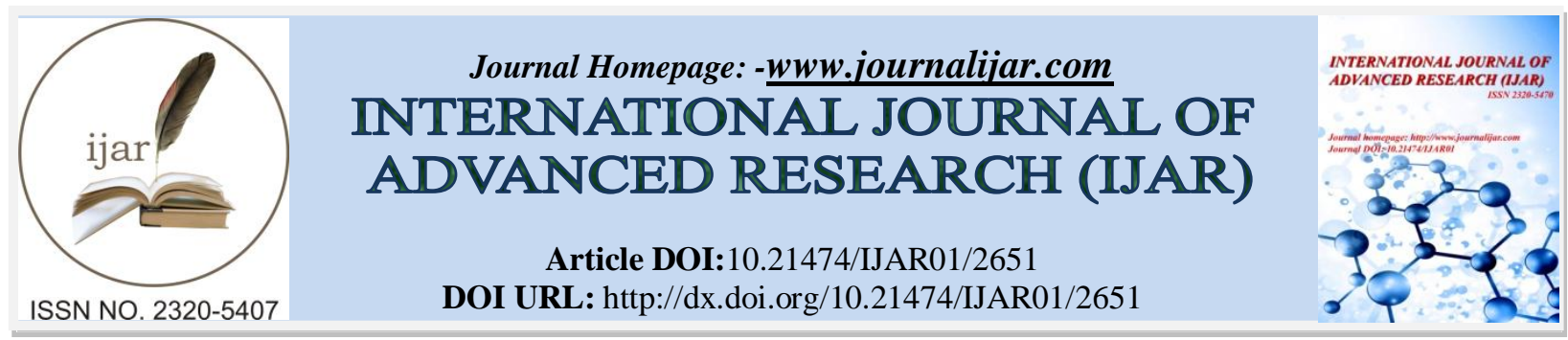

RESEARCH ARTICLE

\title{
PUBLIC AWARENESS AND ATTITUDE OF THE HAZARDS OF CARBON MONOXIDE (CO) POISONING AND THE SAFETY PRECAUTIONS APPLIED TO THAT REGARD, AMONG SAUDIS FOR THE YEAR 2013-2014.
}

\section{Waseem Hajjar ${ }^{1}$, Abrar Al-Lafi ${ }^{2}$, Abeer Al-Shunifi' ${ }^{2}$ Afnan Al-Hemiddi ${ }^{2}$ and Enas Al-Araik ${ }^{2}$, Ghadah R. Ahmed $^{2}$ and Sara Bin Haddab ${ }^{2}$.}

1. Assistant Professor and Consultant Thoracic Surgeon, Collage of Medicine, King Saud University - Department of Surgery at King Khalid University Hospital, Riyadh.

2. Medical Intern, Collage of Medicine, King Saud University.

\section{Manuscript Info}

Manuscript History

Received: 30 October 2016

Final Accepted: 29 November 2016

Published: December 2016

\section{Abstract}

Background:Carbon monoxide $(\mathrm{CO})$ is a highly poisonous, odorless, colorless and non-irritating gas. It is formed by incomplete combustion of carbon or carbonaceous material.

Because burning under conditions with insufficient oxygen will prevent complete oxidation to carbon dioxide $(\mathrm{CO} 2)$, carbon monoxide gas will be formed. When inhaled, it will prevent absorption of oxygen by combining with hemoglobin in the blood, forming carboxyhemoglobin, which result in secondary tissue hypoxia and cellular damage, hence the name "silent killer".

Objectives:The three main objectives of the study are; (a) Measuring public exposure to $\mathrm{CO}$ producing sources among Saudis using social networking, in winter season for the year 2013-2014, (b) Assessing their awareness and knowledge towards the hazards of carbon monoxide $(\mathrm{CO})$ poisoning produced by different means of heating, and (c) Determine the safety precautions applied to that regard.

Methods:A cross sectional study was conducted online targeting, sample size of 634 Saudis from age of (16-50 years) who are using social networks, regarding: a) The public exposure to different $\mathrm{CO}$ producing sources, b) The public knowledge regarding symptoms, sources and risks, c) The safety precautions followed to prevent unintentional carbon monoxide poisoning

Result:Based on our research, more than half of our sample size $(53.94 \%)$ were exposed to $\mathrm{CO}$ from different sources with difficulty in breathing being the most known symptom chosen by $75.10 \%$ of our sample, followed by headache and dizziness being the second with $(57.10 \%)$ whilst only $11.70 \%$ chose seizures, which is the least symptom, selected. CO poisoning resulted in suffocation and death with $89.11 \%$ and $59.62 \%$ respectively being the most known risks. Burning coal or firewood was the highest selected source of $\mathrm{CO}$ with percentage of $88.60 \%$ however, only $4.70 \%$ thought refrigerators as a 
possible source of CO. On the other hand, More than half of our sample $(55.59 \%)$ do not apply the safety precautions with only $1.7 \%$ own a CO alarm system.

Conclusion:Based on our results, the study showed that a large proportion of Saudis using social networks of age 16-50 years have enough awareness about carbon monoxide poisoning hazards and its manifestations yet not applying safety precautions to that regard including owing $\mathrm{CO}$ alarm systems and routine checkup for their heating appliances.

Copy Right, IJAR, 2016,. All rights reserved.

\section{Introduction:-}

Carbon monoxide ( $\mathrm{CO})$ is a highly poisonous, odorless, colorless and non-irritating gas. It is formed by incomplete combustion of carbon or carbonaceous material. Because burning under conditions with insufficient oxygen will prevent complete oxidation to carbon dioxide (CO2), $\mathrm{CO}$ gas will be formed. When inhaled, it will prevent absorption of oxygen by combining with hemoglobin in the blood, forming carboxyhemoglobin, which result in secondary tissue hypoxia and cellular damage, hence the name "silent killer".

Environmental sources of carbonaceous material, also called organic fossil fuels, include; wood, coal, kerosene, petroleum gas and oil. Equipments powered by internal combustion engines are used in many Saudi household appliances, especially in winter season, and if poorly maintained or are used incorrectly, $\mathrm{CO}$ can build up to dangerous levels.

Examples include; "poorly functioning heating systems, improperly vented fuel-burning devices (e.g. kerosene heaters, charcoal grills, camping stoves (Thomassen et al., 2004), gasoline-powered electrical generators (CDC, 2004)), and motor vehicles operating in poorly ventilated areas (e.g. ice rinks, warehouses, parking garages). ${ }^{[1]}$ However, if appliances are maintained and checked regularly, the amount of CO produced is usually not of significance.

Carbon monoxide is such a remarkable poison due to its non-specific manner in which it may present, individuals may present in either forms; acute or chronic, depending upon the amount and duration of exposure to $\mathrm{CO}$ gas. Short exposure to a high level of $\mathrm{CO}$ gives acute symptoms, while those of chronic result from long exposure to a low level of $\mathrm{CO}$. Initial symptoms of $\mathrm{CO}$ poisoning acute insult include; fatigue, headache, dizziness, nausea and vomiting. Most of these symptoms are vague, thus can get mixed up with some viral infections such as influenza, due to the similarity in both symptoms and presenting time, cold weather. Increasing exposure produces profound symptoms in different organs, but has its most serious impact on the organs with the highest oxygen requirement, the brain and heart, resulting in chest pain, palpitations, confusion, syncope, coma, and seizure Chronic exposure may present with similar symptoms, however with gradual onset and can exacerbate angina and chronic obstructive pulmonary disease as well.

That indeed resulted in the fact that $\mathrm{CO}$ poisoning is the leading cause of death by poisoning in industrialized countries and may be responsible for more than half fatal poisoning worldwide. ${ }^{[2,3,4,5,6,8]}$

Statistics measured the epidemiology of carbon monoxide poisoning for a population of 5.2 million, in West Midlands, in January 1988 to December 1994; results reported 701 hospital admissions and 939 death cases due to carbon monoxide poisoning. The study also recorded demographical details determining people who are at high risk to be harmed by carbon monoxide poisoning. Seasonal distribution reported highest incidence was exclusively during cold seasons in the months October-March due to the use of domestic heaters. Gender and age variations identified the vulnerable population being elderly over the age of 85 , infants and young children as they are unable to prevent the insult, males within the age group of 35-39 with rate of 24.0/100,000 compared to women's rate $19.0 / 100,000$, and people with pulmonary and cardiovascular diseases. Geographic variations stated that rural districts of West Midlands have the highest rates. The overall incidence rate of non-intentional carbon monoxide poisoning was $7.6 / 100,000$, with an annual rate of $1.1 / 100,000 .{ }^{[7]}$ 
Many studies described the level of awareness by owning carbon monoxide detectors in houses. However, most of the owners do not practice the sufficient safety precautions and have inaccurate behaviors and beliefs regarding the placement of appliances. Examples for the prevention actions would be the decent placement and maintenance of those appliances such as generators and heaters, as well as maintaining the function of the carbon monoxide detectors. ${ }^{[8]}$ Another study in Mecklenburg County, United State during 2001, measured residential carbon monoxide alarm prevalence and ordinance awareness. The prevalence of $\mathrm{CO}$ alarm awareness in Mecklenburg County was found to be higher than the country average. ${ }^{[9]}$

Varieties of carbon monoxide sources inside houses have been identified to cause potential harm if they were to be misused or misplaced. Most dangerous of which and was believed to be the primary cause of $\mathrm{CO}$ poisoning indoors is burning of coal or charcoal in ill-ventilated areas as it releases CO-saturated airstream. Charcoal usage inside houses is not common in the United States, although 79 cases were recorded after power outage. The main reasons for burning charcoal indoor was for house heating and cooking, also charcoal grills are common in the US. Increased incidence of $\mathrm{CO}$ poisoning from burning charcoal for cooking was reported in Korea. ${ }^{[10]}$

In Beijing, a study was conducted on August 1, 2005 to July 31, 2007 to discover the Domicile-related carbon monoxide poisoning in winter season. The results showed a monthly variation in number of cases throughout the years. However, the number of cases significantly increases especially in January and September. Indicating that carbon monoxide poisoning in cold months occur in high percentage and is related to the burning of coal for home heating. ${ }^{[11]}$ In the United Arab of Emirates during the period 2007-2009, it was indicated the exclusive occurrence of carbon monoxide poisoning is in winter months. The reason was also the use of charcoal as a source of warmth in closed areas with disregard for safety precautions. ${ }^{[12]}$

Comes second in seriousness, are gas geysers, which are LPG-fueled water heaters and its combustion produces significant amount hazardous gases, important of which is carbon monoxide. Those heaters should be placed outside the bathroom and shouldn't be turned on with the doors closed. ${ }^{[13]}$

A study was conducted for accidental carbon monoxide poisoning and dangers of inadequate ventilation concerning the increasing incidence of accidental poisoning due to coal gas burning. The study also stated that there are other causes of poisoning such as poorly maintained and defected appliances and heaters, coke-burning stoves and faulty gas-pipes. Most of those accidents occur due to lack of awareness of the hazards. The "4 D's of accidental carbon monoxide poisoning" is a concept that declares the contributing factors to poisoning, which are; the decrepit, the diseased, the drugged and the drunk. ${ }^{[14]}$

Throughout a five-year study, in Northwest Iran (2003-2008), 3078 cases were admitted to the hospital and 346 deaths were reported for carbon monoxide poisoning. It was confirmed that most of fatality cases occurred in January due to using gas appliances indoors during winter. There were demographic variations to the outcomes, where least fatal cases were higher in females and those who are over the age of $60 .{ }^{[15]}$

\section{Research Methodology:-}

\section{Study design:-}

Quantitative observational analytic study (cross-sectional study). The study was designed to quantify the percentage of knowledge regarding carbon monoxide poisoning hazards and the suitable safety precautions applied.

\section{Study setting: -}

An uncontrolled and exploratory setting has been selected for our research, using online surveys implies that the study was conducted in its natural environment with no manipulation or control by the researcher, which gives better results for a descriptive research.[16] The study was conducted among Saudis using social networks, we chose this sample for many reasons. First, the Kingdom of Saudi Arabia is the largest Arab state in Western Asia, constituting the bulk, around $80 \%$ of the Arabian Peninsula [17] with a population estimated to consist of 16 million citizens.

Furthermore, Saudi Arabia has a desert climate with extremely high day-time temperatures and a sharp temperature drop at night, In the winter the temperature rarely drops below $32{ }^{\circ} \mathrm{F}\left(0{ }^{\circ} \mathrm{C}\right) .[18]$

In regarding to us choosing Saudis, first; in winter season, large proportion of Saudis are still using the traditional heating methods including charcoal grills, firewood and kerosene heaters that produce CO gas. Second, many Saudi houses have tents (khyam) within the front or backyard, with fireplace as an essential mean of heating. Moreover, 
camping is considered one of the most preferable activities for entertainment for many Saudi families in which wood and charcoal are kept on fire inside the tents.

The use of social networks among Saudis is rapidly increasing within years based on Saudi Communication and Information Technology Commission. In 2001, the percentage of users was 5\%, however, that percentage raised up to $54 \%$ in 2012, and since Saudis of age 16-50 are the predominant users of internet including social networks, that makes using online based surveys the best method in reaching the targeted sample. In addition to that, since all the researchers are residents of Riyadh city, using online survey programs makes collecting the data from the different regions of Saudi Arabia more feasible and convenient.

The research represents a certain category of the Saudi population whose minimal level of education is reading and writing. Together with the fact they are using social networks that indicate in a way their socioeconomic level.

\section{Sample size:-}

No previous studies have measured the incidence of the awareness regarding Carbon Monoxide poisoning hazards and its safety precautions in Saudi Arabia, nor regionally, thus the sample size was determined by using the following equation:

$\mathrm{N}=\mathrm{Z} \alpha^{2} \mathrm{P}(1-\mathrm{P}) / \mathrm{d}^{2}$

$\mathrm{N}=1.96^{2} \times 0.65 \times 0.35 / 0.05^{2}$

$\mathrm{N}=349.5$

$=350$ participants

The calculated sample size was insufficient, so we considered it as our minimum limit.

\section{Sampling technique:-}

The online surveys were randomly distributedvia social networks, and the sample was selected as follow:

\begin{tabular}{|c|c|}
\hline Inclusion criteria & Exclusion criteria \\
\hline $\begin{array}{l}\text { The study included the following variables: } \\
\text { Saudis, both genders using social networks, age (from } \\
16-50 \text { years), with various educational levels, } \\
\text { socioeconomic classes and Saudi regions. }\end{array}$ & $\begin{array}{l}\text { The study excluded the following: } \\
\text { 1- Individuals out of the range } \\
\text { (below } 16 \text { and above } 50 \text { years) } \\
\text { 2- Saudis who were not residents of Saudi Arabia. } \\
\text { 3- Saudis with no networks access. } \\
\text { 4- Saudis who were not registered to any social networks. }\end{array}$ \\
\hline
\end{tabular}

\section{Data collection methods:-}

The survey designed to match our objectives and aims, and the online questionnaire includes four main sections. The first section is socio-demographic information (close ended and open questions) which contains these attributes: name, phone number, gender, age, marital status, income, education levels and residency. The second section designed to evaluate and measure the awareness of the participant regarding carbon monoxide and its poisoning hazards by using close-ended and partially close-ended questions. The third part designed to determine the common sources, risks and symptoms which known by our participants. The fourth part designed to determine what precautions have been taken by the participant regarding carbon monoxide poisoning hazards.

We prepared our online electronic survey in both languages; Arabic and English, the survey is self- administrated questionnaire, distributed in many social networks (e.g. Facebook, Twitter, Whatsapp...etc.), across the Kingdom of Saudi Arabia.

\section{Pilot study:-}

A pilot study was done to determine the sample size. The online survey was distributed via social networks for oneday duration; 20 participants from age of (16-50 years) filled the survey across the Kingdom of Saudi Arabia.

\section{Data analysis plan:-}

All the data were tabulated and analyzed by using Statistical Package for Social Sciences program (SPSS), version 21.0. Descriptive statistics including frequency and percentages were used to summarize the data. A univariate Chi-square test was for comparing the results. A p value less than 0.05 was as significant. 


\section{Objectives, Hypothesis and Rationale:- Objectives:}

- Overall: To assess public awareness, attitude, and understanding of the hazards of carbon monoxide (CO) poisoning produced by means of heating and the safety precautions applied to that regard, among Saudis using social networking, in winter season for the year 2013-2014

- Specific: To determine the percentage of knowledge Saudis using social networks have regarding Carbon Monoxide poisoning produced by different means of heating (e.g. charcoal grills, firewood, kerosene heaters ... etc.) and the safety precautions done in that regard.

\section{Hypotheses:}

- Alternative: We hypothesized that more than half of our sample has minimal knowledge regarding hazards of carbon monoxide poisoning and its safety precautions.

- Null: Our sample has enough ( > $60 \%$ correct answers ) knowledge regarding carbon monoxide poisoning hazards and its safety precautions.

\section{Rationale:}

- No previous studies done to assess the awareness of carbon monoxide poisoning in the Kingdom of Saudi Arabia.

- No previous studies done to assess the level of safety precautions applied regarding carbon monoxide poisoning in the Kingdom of Saudi Arabia.

- According to Saudi Arabia's General Directorate of Civil Defense, there is a large number of unintentional CO poisoning cases reported but not documented.

- We aim in our research to measure the level of awareness of the Saudi population using social networks regarding $\mathrm{CO}$ poisoning, in a way to provide basis for future community awareness researches or even campaigns that may help reducing the number of cases.

\section{Ethical Considerations:-}

1. Confidentiality was considered by keeping participants' data secured and private.

2. Consent was clear and understandable to participants without any ambiguity

3. Participants had the right to withdraw at any time.

4. No rewards were given to participants.

\section{Results:- \\ Demographical details variations:-}

Data represented in [Table 1] are the demographic characteristics of the 634 participants who were asked to answer an eighteen-question online survey. Of those respondents, (33.1\%) were males and (66.9\%) were females.

The two groups were compared according to potential categorical variables including, age, educational level, family income and residential areas. Females generally were the dominate responders across demographical regions.

Among the age distributions group, the majority of them being 16-29 years old with total of (63.1\%), in which $(21.3 \%)$ were males and $(41.8 \%)$ females. The chi-square analysis indicated that there was not a significant difference in age group between male and females $(\mathrm{P}=0.074)$.

Educational levels recorded greater numbers of participants with college education and above (66.6\%) followed by high school (30.6\%), below high school was only (2.8\%).

Comparing the household income ranges, 222 participants have higher income of 10,000 to 20,000 Saudi Riyals with percentage of $(35.0 \%), 184$ participants have higher income with percentage of $(29.0 \%)$, (36\%) of them were recorded to have lower income ranging between lower than 5,000 to 10,000 Saudi Riyals and with P-value of $(\mathrm{P}=0.671)$.

According to residential regions divisions; central, western, eastern, northern, and southern also showed significant differences with percentages of $(68.9 \%),(11.8 \%),(7.7 \%),(6.8 \%)$, and $(4.7 \%)$ respectively. Social status did not differ significantly $(\mathrm{P}=0.415)$, most of the respondents 366 were single (57.7\%), and 268 were married $(42.3 \%)$. 


\begin{tabular}{|c|c|c|c|c|}
\hline Parameter & Total $(\%)$ & Male & Female & $\mathrm{P}$ value \\
\hline $\begin{array}{l}\text { Age: } \\
-(16-29) \\
-(30-39) \\
-(40-50)\end{array}$ & $\begin{array}{l}400(63.1 \%) \\
144(22.7 \%) \\
90(14.2 \%)\end{array}$ & $\begin{array}{l}21.3 \% \\
8.5 \% \\
3.3 \% \\
\end{array}$ & $\begin{array}{l}41.8 \% \\
14.2 \% \\
10.9 \% \\
\end{array}$ & .074 \\
\hline $\begin{array}{l}\text { Educational level: } \\
\text {-Below high school } \\
\text {-High school } \\
\text {-Collage and above }\end{array}$ & $\begin{array}{l}18(2.8 \%) \\
194(30.6 \%) \\
422(66.6 \%)\end{array}$ & $\begin{array}{l}.5 \% \\
11.2 \% \\
21.5 \%\end{array}$ & $\begin{array}{l}2.4 \% \\
19.4 \% \\
45.1 \%\end{array}$ & .182 \\
\hline $\begin{array}{l}\text { Social status: } \\
\text {-Single } \\
\text {-Married }\end{array}$ & $\begin{array}{l}366(57.7 \%) \\
268(42.3 \%)\end{array}$ & $\begin{array}{l}19.4 \% \\
13.7 \%\end{array}$ & $\begin{array}{l}38.3 \% \\
28.5 \%\end{array}$ & .415 \\
\hline $\begin{array}{l}\text { Income: } \\
-<5000 \mathrm{SR} \\
-5000-10.000 \mathrm{SR} \\
-10.000-20.000 \mathrm{SR} \\
->20.000 \mathrm{SR}\end{array}$ & $\begin{array}{l}72(11.4 \%) \\
156(24.6 \%) \\
222(35.0 \%) \\
184(29.0 \%) \\
\end{array}$ & $\begin{array}{l}3.6 \% \\
9.1 \% \\
11.0 \% \\
9.3 \% \\
\end{array}$ & $\begin{array}{l}7.7 \% \\
15.5 \% \\
24.0 \% \\
19.7 \% \\
\end{array}$ & .671 \\
\hline $\begin{array}{l}\text { Residential Area: } \\
\text {-Central region } \\
\text {-Western region } \\
\text {-Eastern region } \\
\text {-Northern region } \\
\text {-Southern region }\end{array}$ & $\begin{array}{l}437(68.9 \%) \\
75(11.8 \%) \\
49(7.7 \%) \\
43(6.8 \%) \\
30(4.7 \%)\end{array}$ & & & \\
\hline
\end{tabular}

Responses to carbon monoxide poisoning awareness questions:-

The participants were asked to answer questions about the heating methods applied during cold seasons, which assesses their possible exposure to carbon monoxide and its hazards and the level of awareness to that regard. The answers are categorized into; yes, no and (sometimes /uncertain) were added under the state of yes or no according to the hypothesis question.

Questions number one and two, were concerned about the use of firewood to provide warmth inside houses and inside tents when camping and the results were as follow, $440(69.4 \%)$ were negative to using firewood inside houses, and 194(30.6\%) were positive. Likewise, 132(20.8\%) do not use it inside tents, 502(79.2\%) answered yes.

Some uses air-conditioning units as a mean to provide heat, for that, respondents were asked about the usage of AC units inside houses and in cars, Most of responses were positive 433( 68.3\%) for usage inside houses, On the other hand, the usage of AC units inside cars reported 391(61.7\%) of them were positive, 243(38.3\%) negative answers.

A question was asked to assesses if respondents know the importance of ventilating the place while burning firewood ,Total number of participants who are not aware is 78(12.3\%) and 556(87.7\%) were aware.

Twenty-four (3.8\%) agreed with the statement "Do you think that sleeping next to burning firewood is safe?" and $610(96.2 \%)$ disagreed.

Participants were asked if they believe it is safe to keep heating appliances working while sleeping, 174(27.4\%) answered yes, and 460(72.6\%) answered no, Most of the respondents 505(79.6\%) do not frequently get their gasfueled heating appliances checked by specialists.

Furthermore, respondents were asked, "Do you believe that lowering your car's windows while AC is on is safer for passengers?" 264(41.6\%) agreed with the statement, 370(58.4\%) disagreed,

Additionally, only 70(11\%) own fire alarm systems. 564(89\%) don't have detectors, Greatest bulk doesn't own CO detectors $623(98.3 \%$ ) as well as , they were asked if they owned a fire or CO detectors systems would they get them periodically inspected, 180(29.3\%) answered yes, 448(70.7) answered that they wouldn't.

Finally, respondents were asked about the known sources of carbon monoxide, risks of the exposure, and the symptoms of poisoning for further assessment of the level of the population's awareness. Results are presented with percentages in [table 2]. 


\begin{tabular}{|c|c|c|}
\hline \multicolumn{3}{|c|}{ Risks } \\
\hline & Responses & Percentage \\
\hline Uncertain & 90 & $14.19 \%$ \\
\hline Suffocation & 565 & $89.11 \%$ \\
\hline Death & 378 & $59.62 \%$ \\
\hline Poisoning & 201 & $31.70 \%$ \\
\hline Damage to brain cells & 247 & $38.95 \%$ \\
\hline Heart attack & 204 & $32.17 \%$ \\
\hline \multicolumn{3}{|c|}{ Sources } \\
\hline Uncertain & 95 & $14.90 \%$ \\
\hline Burning coal or firewood & 562 & $88.60 \%$ \\
\hline Coal grills & 325 & $51.30 \%$ \\
\hline Heating appliances fueled by gas & 308 & $48.60 \%$ \\
\hline Car engines and exhausts & 380 & $59.90 \%$ \\
\hline Smoke from fires & 473 & $74.60 \%$ \\
\hline Refrigerators & 30 & $4.70 \%$ \\
\hline Generators & 81 & $12.80 \%$ \\
\hline \multicolumn{3}{|c|}{ Symptoms } \\
\hline Uncertain & 163 & 0.257 \\
\hline Difficulty in breathing & 476 & $75.10 \%$ \\
\hline Palpitations & 226 & $35.60 \%$ \\
\hline Headache and dizziness & 362 & $57.10 \%$ \\
\hline Nausea and vomiting & 196 & $30.90 \%$ \\
\hline Lethargy and sluggishness & 213 & $33.60 \%$ \\
\hline Memory and walk disturbances & 109 & $17.20 \%$ \\
\hline Hallucination & 80 & $12.60 \%$ \\
\hline Seizures & 86 & $13.60 \%$ \\
\hline Tremors & 74 & $11.70 \%$ \\
\hline
\end{tabular}

\section{Discussion:-}

Saudis use different means of heating that can produce carbon monoxide, the remarkable poison due to its nonspecific manner in which it may present. We chose our topic because there were no previous studies done to assess the awareness and the level of safety precautions applied regarding carbon monoxide poisoning in the Kingdom of Saudi Arabia. In addition, according to Saudi Arabia's General Directorate of Civil Defense, there is a large number of unintentional $\mathrm{CO}$ poisoning cases reported but not documented.

Our study was conducted among Saudis using social networking from age of 16-50 years in winter season for the year 2013-2014 because the use of internet, including social networks, among Saudis is rapidly increasing within years based on Saudi Communication and Information Technology Commission. Since Saudis of age 16-50 are the predominant users of social networks, which makes using online-based surveys the best method in reaching the targeted sample.

Our aim in this study was to measure the level of awareness of the Saudi population using social networks regarding $\mathrm{CO}$ poisoning, in a way to provide basis for future researches or even public health prevention strategies, like campaigns, that may help reducing the number of cases. In this research, we measured (a) public awareness, attitude, and understanding of the hazards of carbon monoxide poisoning produced by means of heating, and (b) the safety precautions applied to that regard. Based on the Social clinic Statistics, we correlate the finding with the three million Saudi Twitter users, we get $(2,247,000)$ aware Twitter users and with the six million Saudi Facebook users, we get $(4,494,000)$ aware Facebook users and so on.

We reached our conclusion about the safety precautions applied to prevent carbon monoxide poisoning by filling an -18 questions -survey asking about; (a) making sure the place is ventilated when using firewood, (b) putting off 
burning firewood after use and (c) making sure that their heating appliances are frequently checked by a specialist. Results showed that $87.7 \%$ of sample make sure the place is ventilated when using firewood, however $60.6 \%$ do not make sure that a specialist frequently checks their heating home appliances.

The results of this study indicate that a large proportion of Saudis using social networks of age 16-50 years have enough awareness about carbon monoxide poisoning hazards and its manifestations yet not applying safety precautions to that regard. The results that measured the awareness of $\mathrm{CO}$ poisoning were unexpected comparing to our hypothesis.

In fact, most of the respondents surveyed in winter season 2013-2014 - the majority of respondents with high educational level "College \& above " — did not own a CO alarm. These findings are not consistent with those of previous studies based in countries other than Saudi Arabia. In fact, a study titled "Residential carbon monoxide alarm prevalence and ordinance awareness" that took place in the US for the year 2012 May-Jun, resulted in the fact that $67.8 \%$ of their sample reported having a working CO alarm. In our study however, $89 \%$ reported not having a $\mathrm{CO}$ alarm system at all. [9] That information is of great importance because it indicates that our country is in desperate need for raising the awareness about the importance of the use of carbon monoxide alarms.

Unfortunately, although most respondents in our study were aware of common risks, sources and symptoms of the $\mathrm{CO}$ poisoning and its manifestations, only $1.7 \%$ reported owning a $\mathrm{CO}$ alarm system, even though $\mathrm{CO}$ alarms are inexpensive -usually less than $\$ 25$ - and widely available [8] This finding is of concern because similar studies that took place in the US showed that:(a)Fuel-burning home heating systems continue to be a leading source of fatal CO Poisonings each year. [19] (b) More than half of all CO-related deaths could be prevented by use of a CO detector. [20] (c) Evidence is emerging that country policies mandating the use of $\mathrm{CO}$ detectors in residential settings can reduce poisonings and deaths. [21]

\section{Limitations:-}

This study had several limitations, including:

1. The survey may be influenced by selection bias because it was distributed via certain social networks, so the survey is limited only for individuals who have the access to the networks.

2. Data tends to be biased to central region of Saudi Arabia (Riyadh). As a result, the data was not representative for all Saudis.

3. Some of the collected data underwent recall bias and information bias, as some of the participants couldn't remember certain information

4. The online survey was self-administrated, which may include inaccurate responses.

5. The study measured the awareness of co poisoning at one point in time. As a result, we cannot observe any change in the level of awareness and the applying of safety precaution.

6. The questioner had not been previously validated. Therefore, it cannot be use globally.

\section{Conclusion:-}

Based on our results, this study shows that a large proportion of Saudis using social networks of age 16-50 years have enough awareness about carbon monoxide poisoning hazards and its manifestations, yet not applying the proper safety precautions to that regard, like not owing a $\mathrm{CO}$ alarm system nor doing routine checkups for their heating appliances.

In comparison between age groups, older participants showed a higher level of awareness about CO poisoning than does younger.

\section{Recommendations:-}

At the end of our research project, we would recommend the following:

- Carbon monoxide poisoning can be prevented by Establishing a well-prepared centers or campaigns aim to train the citizen with different age groups who have minimal knowledge to apply the proper and the convenient precautions that help in minimizing the number of cases suffering from carbon monoxide poisoning.

- Government may convince the citizen to do a routine checkup for their heating appliance.

- Researches should be concern about carbon monoxide poisoning hazards and the safety precautions applied to that regard, especially there was no previous studies was done regarding this topic in Kingdom of Saudi Arabia 
- Reliable documentation for all cases of unintentional carbon monoxide poisoning.

\section{Acknowledgment:-}

We are grateful for our supervisor Dr.WaseemHajjar for giving us the chance to be co-investigators for the first time in the research field; we also appreciate his enthusiasm and cooperation.

We would also like to thank Dr. Raju Kumar Mandal, who was of most assistance to us throughout this research, for his guidance and patience with us.

\section{References:-}

1. ADIKE, J. 2012. ASSESSMENT OF CARBON MONOXIDE (CO) LEVEL IN ENUGU METROPOLIS MONITORING INDUSTRIAL AND RESIDENTIAL AREA. [e-book] ENUGU STATE: Caritas University Amorji-Nike Enugu. p. 37,38. http://goo.gl/dIR9S4 [Accessed: 9 Nov 2013].

2. Hardy K, Thom S. Pathophysiology and treatment of carbon monoxide poisoning. J ToxicolClinToxicol.. 1994; 32 (6): 613--629. Available from PubMed: http://www.ncbi.nlm.nih.gov/pubmed/7966524

3. Guzman J. Carbon monoxide poisoning. Crit Care Clin. 2012; 28 (4): 537-48. [Accessed 9 Nov 2013]. Available from PubMed: http://www.ncbi.nlm.nih.gov/pubmed/22998990

4. Henry J. Carbon monoxide: not gone, not to be forgotten. J AccidEmergMed.. 1999; 16 (2): 91.

5. Detecting Carbon Monoxide Poisoning in the Emergency Department. 2008. [e-book] Irvine, California: Masimo $\begin{array}{llll}\text { Corporation. } & \text { [Accessed: } & 9 & \text { Nov 2013]. Available through: }\end{array}$ Masimo.comhttp://www.masimo.com/pdf/whitepaper/LAB4425B.pdf

6. Unknown author. Protect Your Family and Yourself from Carbon Monoxide Poisoning. [e-book]; 1996. Available from: http://www.epa.gov/iaq/pdfs/co_factsheet_en.pdf.

7. Wilson R, Saunders P, Smith G. An epidemiological study of acute carbon monoxide poisoning in the West Midlands. Occup Environ Med. 1998; 55 (11): 723--728. Available from PMC: http://www.ncbi.nlm.nih.gov/pmc/articles/PMC1757528/

8. King M, Damon S. Attitudes about carbon monoxide safety in the United States: results from the 2005 and 2006 HealthStyles survey. Public Health Rep. 2011; 126 (Suppl 1): 100. Available from PMC: http://www.ncbi.nlm.nih.gov/pmc/articles/PMC3072908/

9. Iqbal S, Clower J, Saha S, Boehmer T, Yip F, Cobb R, Flanders W, Mattson C. Residential carbon monoxide alarm prevalence and ordinance awareness. JPHMP. 2012; 18 (3): 272-278. [Accessed 7 Nov 2013]. Available from PubMed: http://goo.gl/8JguQV

10. Hampson N, Kramer C, Dunford R, Norkool D. Carbon monoxide poisoning from indoor burning of charcoal briquets. JAMA. 1994; 271 (1): 52--53. Available from PubMed: http://goo.gl/UY7Mx3

11. Du T, Zhang Y, Wu J, Wang H, Ji X, Xu T, Li Y, Xu L, Lewin M. Domicile-related carbon monoxide poisoning in cold months and its relation with climatic factors. Am J Emerg Med. 2010; 28 (8): 928--932. Available From PubMed: http://goo.gl/VFHfVJ

12. Al Kaabi J, Wheatley A, Barss P, Shamsi M, Lababidi A, Mushtaq A. Carbon monoxide poisoning in the United Arab Emirates. Int J Occup Environ Health. 2011; 17 (3): 202--209. Available from PubMed: http://goo.gl/7VW4P6

13. Sharma S, Gupta R, Paul B, Puri S, Garg S. Accidental carbon monoxide poisoning in our homes. Indian J Crit Care Med. 2009; 13 (3): 169. Available from PMC: http://www.ncbi.nlm.nih.gov/pmc/articles/PMC2823102/

14. Fiddes F. Accidental Carbon Monoxide Poisoning. BMJ. 1956; 2 (4994): 697. Available from PMC: http://www.ncbi.nlm.nih.gov/pmc/articles/PMC2035194/

15. Nazari J, Dianat I, Stedmon A. Unintentional carbon monoxide poisoning in Northwest Iran: a 5 -year study. $J$ Forensic Leg Med. 2010; 17 (7): 388--391. Available from PubMed: http://goo.gl/rFaw4X

16. Avan, B. and White, F. 2001. Why a research study needs a design?. JPMA, 51 (197).

17. Stokes, Jamie (2009). Encyclopedia of the Peoples of Africa and the Middle East, Volume 1. p. 605. ISBN978-08160-7158-6.

18. "Saudi Arabia". Weather Online. Retrieved 30 July 2011.

19. Consumer Product Safety Commission (US). Non-fire carbon monoxide deaths associated with the use of consumer products: 2002 annual estimates [cited 2006 Jul 11]. Available from: URL:http://www.cpsc.gov/LIBRARY/co05.pdf

20. Yoon SS, Macdonald SC, Parrish RG. Deaths from unintentional carbon monoxide poisoning and potential for prevention with carbon monoxide detectors. JAMA 1998;279:685-7

21. Broder J, Mehrotra A, Tintinalli J. Injuries from the 2002 North Carolina ice storm, and strategies for prevention. Injury 2005;36: 21-6 